engagement with stakeholders, including the CCG. The focus of improved patient experience, safety, and clinical effectiveness was maintained. The innovation allowed a greater focus on enabling patients' to maintain their independence in managing their medicines.

\section{P-129 THE ESSENCE OF TIME - CAN AUTOMATED DISPENSING RELEASE HOSPICE NURSING TIME FOR PATIENT CARE?}

Tracy Livingstone, Nan Jones. Nightingale House Hospice, Wrexham, UK

\subsection{6/bmjspcare-2016-001245.152}

While there is research supporting the benefit of automated dispensing for the prevention of medication errors in emergency departments Fanning et al. (2015) this has not previously been looked at in a hospice setting neither has the impact of automated dispensing and top-up on releasing nurses time to spend with patients in this area.

With the likelihood of increasing demand for hospice services and increasing complexity of patient needs there is a drive to provide more care from the same or even less resource, technology ranging from telemedicine and remote monitoring to automated systems may provide an opportunity to increase our ability to meet these challenges and free up nurses to focus on the provision of patient contact and care that hospices are historically associated with.

This presentation follows the journey within a 12-bedded inpatient hospice of installation of automated dispensing medication system in a hospice in-patient unit, from the point of pre installation time and motion studies of medication dispensing through installation and beyond investigating the impact on:-

- System acceptability to staff

- Nurse time taken to dispense

- Nurse time taken to complete stock checks and weekly top-up

- Nurse satisfaction with system following installation

- pre and post installation medication error rates.

In addition the presentation reflects the benefit of considering change proactively rather than as a response to critical incidents with medication and the significant impact this can have on staff confidence and morale within a small team.

\section{P-130 "JUST IN CASE" BAGS - WHAT IS THE VALUE OF ANTICIPATORY PRESCRIBING ON DISCHARGE FROM AN ACUTE TRUST?}

\footnotetext{
1,2 Helen Lock, ${ }^{2}$ Simon Haslam, ${ }^{2}$ Alice King, ${ }^{2}$ Caroline Pinckney, ${ }^{2}$ Rameshwor Sunar, ${ }^{2}$ Jennifer Barry, ${ }^{1,2}$ Becky Baines. ${ }^{1}$ Hospiscare, Exeter, UK; ${ }^{2}$ Royal Devon and Exeter NHS Foundation Trust
}

\subsection{6/bmjspcare-2016-001245.153}

The concept of "Just in Case" bags to support anticipatory prescribing in end of life care is not new, but there is little research evidence to support their use - anecdote and small audit level evidence at best. The recent 2015 NICE guidance on care of the dying patient highlighted the lack of evidence and specifically suggested more research into this topic.

In our rural community (population 380,000), "Just in Case" bags have been used in practice for many years. Over the last two years, it has been usual practice to dispense small supplies of "Just in Case" medication on discharge from our large, 75bedded acute trust.

The usefulness of Just in Case bags is being reviewed in a number of ways:

1. Retrospective review of hospital and specialist palliative care records of a cohort of patients discharged over a six-month period with "Just in Case" medication

2. Attempts are being made to determine appropriateness, usage and effectiveness of symptom control

3. Estimation of costs

4. Preferred and actual place of death

5. Detailed review of patients prescribed "renal friendly" drugs checking for appropriateness and effectiveness.

An analysis of problems associated with Just in Case bags will be undertaken and attempts to improve the process will be undertaken using quality improvement methodology.

The work is being developed by a team of junior doctors in the Trust, with the support of the specialist palliative care lead consultant and registrar. We also aim to show that by working closely with the lead prescribers of these medications (junior doctors) we can highlight the appropriate use and potential benefits of "Just in Case" bags in a more systematic way. At the same time we hope that this project will enhance more general awareness of end of life care beyond the acute hospital in this key group of staff.

\section{P-131 ENHANCING MEDICINES SAFETY - SMALL CHANGES LEAD TO BIG IMPROVEMENTS!}

${ }^{1}$ Kate Marley, ${ }^{1}$ Carole Slocombe, ${ }^{1}$ Clare Doyle, ${ }^{2}$ Graham Holland. 'Woodlands Hospice, Liverpool, UK; ${ }^{2}$ Liverpool Heart and Chest Hospital

\subsection{6/bmjspcare-2016-001245.154}

Introduction Woodlands Hospice has a transparent approach to incident reporting and staff are encouraged to report near misses. In 2014/15, 76 medicines administration errors were reported, many relating to incomplete documentation. 'Enhancing medicines safety and reducing documentation errors' was chosen as an organisational priority for 2015/16.

Actions Improvements were led by the hospice's Medicines Management Group. A revised medicines management policy was implemented and the annual medicines training programme revised.

Inpatient nurses were consulted for their ideas about improvements in medicines safety and 'fact-finding' visits were made to local hospices. All practical ideas were considered and the following were implemented:

- A 'Woody' sign (based on the hospice rabbit mascot) was designed as an aide-memoire to be placed on bedroom doors to indicate that a medicines-related action needs to be completed e.g. return to administer heparin

- An additional medicine trolley was purchased to reduce the number of patients on each medicine round

- A Controlled Drug checklist was devised to ensure daily completion of documentation.

Results Medicines administration incidents for the year 2015/16 reduced from 76 to 25 .

Additional benefits included: 
- Reduced pressure on nursing staff with more nurses sharing the burden of medicines rounds with round size reducing from $7 / 8$ patients to 5 patients

- Patients receiving their medicines in a more timely fashion; staff able to spend more time on clinical care

- 'Woody' is a valuable reminder to staff to return to patients if necessary

- Controlled Drug documentation is checked and completed daily.

Conclusion Focusing on policy implementation and revising medicines training results in a measurable reduction in documentation errors. However, involving a wider team in developing simple, practical ideas leads to improved medicines administration for patients; reduced pressure on nurses; and better staff morale.

Small changes really can lead to big improvements.

\section{P-132 DEMENTIA IN A HOSPICE? WHERE DO WE START?}

1,2Sharron Tolman. 'St Cuthbert's Hospice, Durham, UK; ${ }^{2}$ Dementia UK

\subsection{6/bmjspcare-2016-001245.155}

I joined St Cuthbert's Hospice as an Admiral Nurse in 2014. Many hospices have contacted us since to enquire about our work so I thought this would be a good opportunity to share what we have achieved so far.

We began with challenging the fear and stigma of dementia by raising awareness among all staff, from all departments, some becoming dementia friends and champions. A gentleman with dementia helped us with improved signage to reduce confusion and aid orientation throughout the building. We were talking about dementia more, seeing the person first, and bringing it into mandatory training for staff and volunteers. We built on compassion and confidence to care, embedding assessments which would impact on improved care outcomes and safety-specific tools for cognitive testing, pain, delirium and depression. We helped staff understand the difference between the 3 Ds - delirium, depression and dementia - and the importance of knowing this to provide the most appropriate intervention. We developed a delirium leaflet for patients and carers to help people understand what is happening to them when they are confused and how carers can help.

At the same time, we engaged with the community and all the other dementia care providers. Positive, collaborative relationships emerged, encouraging referrals and an understanding of what else is out there. If the hospice can't help, who can? We provide telephone, website and face to face contact for carers of people with dementia, at all stages of the illness but more commonly in the moderate to late stages as things are changing and carers are hitting crisis points. We are developing a volunteer-led project, providing companionship to those with advanced dementia at home, looking at new ways of communicating as verbal skills are lost and we have plans for cognitive stimulation groups for people with mild to moderate dementia. Exciting times!

\section{P-133 HOSPICE ENABLED DEMENTIA CARE: EXPLORING A PATIENT AND CARER LED COLLABORATIVE HUB RESOURCE}

Maddy Bass, John Hunt. St John's Hospice, Lancaster, UK

10.1136/bmjspcare-2016-001245.156
'Hospice enabled dementia care: [hospices as] key partners working with their local community and care economy to ensure people affected with dementia have access to optimum palliative care and support wherever they live and wherever they need it, regardless off anticipated prognosis'.

St John's Hospice is committed to reaching out to people affected by dementia and is developing a strategic action plan and partnerships to best support individuals with a dementia diagnosis and those closest to them.

In order that the most effective assistance, information and care is made available, the hospice, together with NHS, social care, legal and university researcher colleagues has adopted a pilot model developed by a voluntary group, Lancashire Dementia Voices (LDV) within the region. In March 2016, this independent group of people living with dementia, launched a project to provide a 'one-stop shop' resource, regularly monthly and with themes and speakers to ensure up-to-date information, advice and support is readily available.

St John's Hospice and its partners see this 'Hub' resource as a potentially creative and collaborative development. Its first action is to seek the views of people living with dementia, through a 'listening event' to be held at the hospice in early June 2016. Information will be disseminated directly to individuals and their carers, identified through NHS services. It is also hoped that this event will generate interest for volunteers from the target group to join the multiple agencies in a steering group to determine the structure, venue, initial programme and regularity of the 'Hub' service.

The hospice views this as part of its increasing community engagement and will review and evaluate its contribution to the project. By absorbing the views of people affected by dementia, and their carers, the hospice hopes to ensure delivery of dementia-friendly and effective inpatient, outpatient and home services.

\section{P-134 HOSPICE AND DEMENTIA CARE: INNOVATION AND COLLABORATION}

Heather Watson. Dorothy House Hospice Care, Bradford on Avon, UK

\subsection{6/bmjspcare-2016-001245.157}

Background While few people challenge the belief that dementia is a life-limiting illness, it has struggled to be accorded the same degree of service provision within the palliative care domain as other life-limiting illnesses (Hospice UK, 2015). There are differing reasons for this ranging from the historical focus of hospice care which has traditionally not included individuals with a dementia diagnosis, to concerns about knowledge and skills of staff, and resource implications of an extending service.

Key Issues Referrals to the hospice for people with dementia are generally low. Anecdotal evidence from discussions with local dementia services highlighted that many staff are aware of the role of hospice care in dementia. The Hospice Dementia Working Group therefore reviewed its provision of end of life care for people with dementia identifying areas for development mapped against the Southwest Hospital Standards in Dementia Care.

Method Following the review a dementia strategy was developed with six key actions for the next year: To develop a Dementia friendly environment; Workforce dementia awareness training for all staff; The rollout of a training programme for dementia care professionals to support end-of-life care locally, raising awareness of the role of hospice care; Representation at local dementia strategy groups to contribute an end of life perspective 